\title{
Rhizosphere Processes and Nutrient Management for Improving Nutrient-use Efficiency in Macadamia Production
}

\author{
Xin Zhao and Qianqian Dong \\ Department of Plant Nutrition, China Agricultural University, Key \\ Laboratory of Plant-Soil Interactions, Ministry of Education, Beijing \\ 100193, P. R. China \\ Shubang Ni, Xiyong He, Hai Yue, and Liang Tao \\ Yunnan Institute of Tropical Crops, Jinghong 666100, Yunnan, P. R. China \\ Yanli Nie \\ The General Station of Forestry Technology Extension in Yunnan Province, \\ Yunnan, P. R. China \\ Caixian Tang \\ Department of Animal, Plant and Soil Sciences, AgriBio - Centre for \\ AgriBioscience, La Trobe University, Bundoora, Victoria 3086, Australia
}

Fusuo Zhang and Jianbo Shen ${ }^{1}$

Department of Plant Nutrition, China Agricultural University, Key Laboratory of Plant-Soil Interactions, Ministry of Education, Beijing 100193, P. R. China

Additional index words. proteoid roots, nutrient mobilization, orchard, sustainability, rhizosphere nutrition

\begin{abstract}
Macadamia (Macadamia spp.) has been widely planted in southern China and has been now developed into an important industry. China has the largest area of macadamia plantation in the world but provides only $3 \%$ production of the world. Current farming systems have a fertilizer surplus of about $73 \mathrm{~g}$ of nitrogen $(\mathrm{N}), 103 \mathrm{~g}$ of phosphorus (P), and $24 \mathrm{~g}$ of potassium (K) per macadamia plant per year in southern China. Optimizing fertilization recommended for macadamia improves production by about $5 \mathrm{~kg}$ per plant. Macadamia develops cluster roots (i.e., proteoid roots) in a $\mathbf{P}$ starvation environment. Overuse of $P$ fertilizers restrains the development of cluster roots as well as rhizosphere processes, thus decreasing the $P$-use efficiency. Excessive fertilization, especially $P$ fertilization, is one of the major limiting factors in China macadamia production. This study is the first to analyze current management practices and then discuss approaches of improving nutrient management based on the specific root biology of macadamia. For a sustainable macadamia industry, it is imperative to develop appropriate nutrient management by integrating root-zone soil nutrient supply, fertilizer application, and rhizosphere processes.
\end{abstract}

Macadamia is an evergreen orchard crop (Duke, 2001; Storey and Hamilton, 1953) and belongs to the Proteaceae family (Peace et al., 2003). Its kernel contains more than $72 \%$ oil and is regarded as one of the most important nuts in the world due to its high nutritional

Received for publication 9 Oct. 2018. Accepted for publication 19 Dec. 2018.

This paper was presented as a part of the 2017 International Macadamia Research Symposium, 13-14 Sept. 2017, in Big Island, HI.

This study was supported by the National Key Research and Development Program of China (2017YFD0200200, 2016YFE0101100), National Natural Science Foundation of China (31772402, 31330070), and Yun-Tian-Hua Group special funding of Yunnan in China (YTHZWYJY2016007).

${ }^{1}$ Corresponding author. E-mail: jbshen@cau.edu.cn. value (Quinlan and Wilk, 2005). Macadamia species originated in southeast Queensland and northeast New South Wales (Quinlan and Wilk, 2005; Stephenson, 2005) and grew in soils with a low supply of nutrients, particularly P. These species develop cluster roots and are adapted to low-P stresses associated with infertile soils (Stephenson, 2005) through increasing root exudation of carboxylates, protons, and acid phosphatases in the rhizosphere, thus mobilizing inorganic and organic P from the soils (Hue, 2009; Shen et al., 2011).

Macadamia has been introduced into many countries around the world (Ko, 2009). China has the largest planting area of macadamia in the world, with rapid expansion in the past decade (He et al., 2017). However, soil and nutrient management for macadamia production is still in its infancy. Many guide brochures on the Macadamia grower's handbook have been used in Australia and America (Bittenbender and Hirae, 1990; O'Hare et al., 2004). The technical guidelines mentioned in these books are not well adapted to the local soil and climatic conditions in China. Moreover, the unique characteristics of cluster roots of macadamia have been greatly ignored, leading to uncoupling of crop management in the orchard with root/rhizosphere-based nutrient management. Enhancing nutrient-use efficiency through optimizing fertilizer input, improving fertilizer formulation, and maximizing biological interaction effects helps develop healthy and sustainable orchards (Jiao et al., 2016; Shen et al., 2013).

This paper discusses the problems and challenges of macadamia production and development in China as well as other parts of the world, analyzes how cluster root growth affects the rhizosphere dynamics of macadamia, thus contributing to efficient nutrient mobilization and use, and puts forward the strategies of nutrient management for improving nutrient-use efficiency in sustainable macadamia production.

\section{Macadamia Development in China: Problems and Challenges}

Macadamia is grown in Australia, China, South Africa, America, Kenya, Guatemala, and some other countries (Trueman, 2013). It has been widely planted in southern China since the 1970 s due to its high profitability. China has become the largest planting region in the world (He et al., 2017). In 2015, China's planting area was about 128,000 ha, accounting for $58 \%$ of the production area in the world (He et al., 2017). One year later in 2016 , the planting area of China increased by $25 \%$ and reached 160,000 ha (unpublished data from Yunnan Institute of Tropical Crops). Yunnan province has the largest planting area of macadamia in China, accounting for $94 \%$ of total planting area, followed by Guangxi and Guizhou provinces (Fig. 1). According to the local government plan, macadamia planting area will be projected to reach 260,000 ha in Yunnan province by 2020. Although largest in planting area, the nut production in China is relatively low (Fig. 2A), with only 3\% (kernels) of the world production during the past 5 years (International Nut and Dried Fruit Council, 2016/2017). Australia, South Africa, and Kenya produce almost $70 \%$ of macadamia nuts in the world, followed by Hawaii (International Nut and Dried Fruit Council, 2016/2017) (Fig. 2B). The Australian macadamia industry adopts integrated management approaches to sustain high productivity for the orchards, including management of canopy, orchard floor, and drainage (Bright et al., 2016). It has been recommended to apply fertilizers at small amounts (according to the soil analysis) every 8 weeks during the growing season from spring to autumn. For bearing trees, both leaf and soil samples need 

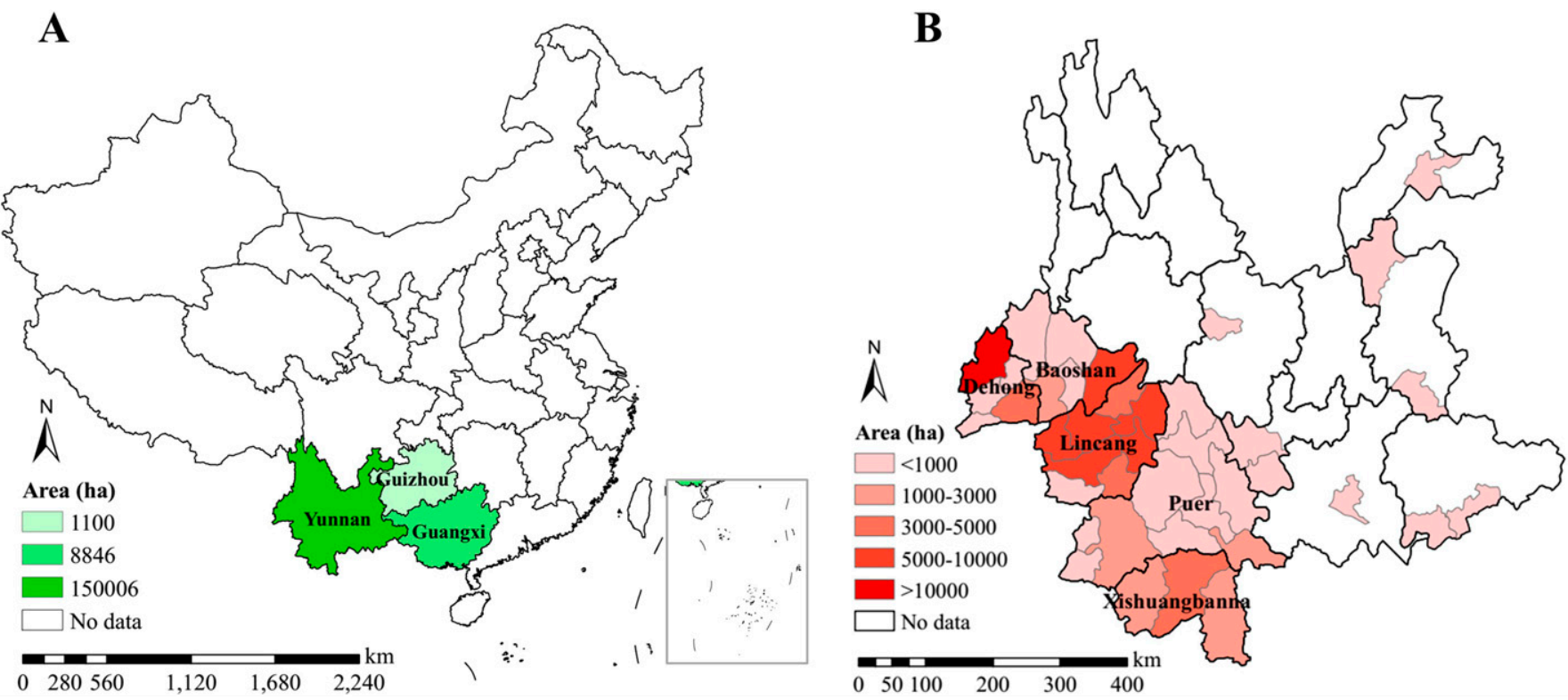

Fig. 1. Planting area of macadamia in China (A) and the Yunnan province (B) in 2015. Yunnan has the largest planting area in China, including the Lincang, Dehong, Puer, Baoshan, and Xishuangbanna districts. The data of planting areas were collected from Yunnan Institute of Tropical Crops and the General Station of Forestry Technology Extension in Yunnan Province.

A

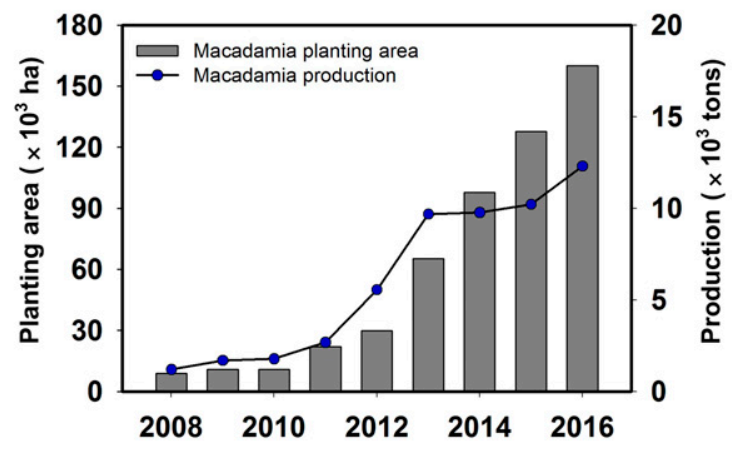

B

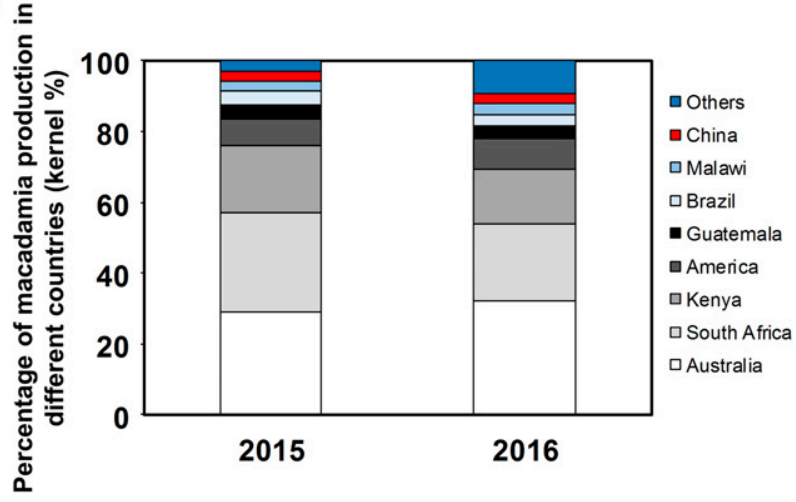

Fig. 2. Macadamia planting area and nut production (in-shell) in China from 2008 to 2016 (A) (data from Yunnan Institute of Tropical Crops), and percentage of macadamia production (kernel) in different countries (B) (International Nut and Dried Fruit Council, 2016/2017). The data of China's planting areas and production of macadamia from 2008 to 2016 were collected from the literature (He et al., 2017) and the General Station of Forestry Technology Extension in Yunnan Province. The data regarding production (kernel) in different countries were collected from International Nut and Dried Fruit Council.

to be analyzed every year to guide the fertilizer recommendation. Where irrigation is available, water is supplied after each application of fertilizer under the canopy (O'Hare et al., 2004). The main planting areas of macadamia, such as the Yunnan and Guangxi provinces in China, are mountainous regions with no drainage system, and therefore many guides for macadamia production in Australia are not suitable for China. The agronomic management of macadamia, especially nutrient management, is lacking effective guidance because of a poor understanding of biological characteristics of nutrient uptake and demand and root growth and rhizosphere dynamics of the plant species.

In southwestern China, macadamia usually has a peak flowering in March. From May to June is the period of fruit expansion. Oil accumulation usually occurs in the periods of July and August. The fruit ripens in September. After harvest, the macadamia plants need to recover the vegetative growth, and so more nutrients are needed. According to this pattern of macadamia growth and nutrient demands, fertilization should be applied in February, May, July, and October, which matches the key growth periods of the macadamia. However, our survey across 39 farm field sites in southern China showed that $43 \%$ farmers apply fertilization twice annually and that all the fertilizer times are optional and unstable. About 51\% farmers apply fertilizers by broadcasting. More than $50 \%$ farmers consider "more fertilizer resulting in more production." The survey also showed that the conventional application rates of fertilizer nutrients are $314 \mathrm{~g}$ of $\mathrm{N}, 127 \mathrm{~g}$ of $\mathrm{P}$, and 247 of $\mathrm{K} g$ per tree. However, nutrient requirements are about $241 \mathrm{~g}$ of $\mathrm{N}, 24 \mathrm{~g}$ of $\mathrm{P}$, and $223 \mathrm{~g}$ of $\mathrm{K}$ per bearing tree annually based on the calculation of nutrient balance (requirements = annual removal of nutrients by harvested nuts + additional growth of canopy). The fertilizer inputs by farmers, especially for $\mathrm{P}$, are much greater in the current practices than the nutrient requirement for macadamia production, with a nutrient surplus of $73 \mathrm{~g}$ of $\mathrm{N}, 103 \mathrm{~g}$ of $\mathrm{P}$, and $24 \mathrm{~g}$ of $\mathrm{K}$ per macadamia plant (Fig. 3). Also, fertilizer types vary, with no unified standard for optimal use. Local growers in Yunnan province mostly use the $15 \mathrm{~N}-7 \mathrm{P}-12 \mathrm{~K}$ compound fertilizer, which is recommended for cereal crops. More than seven different combinations of fertilizers are used by farmers. 


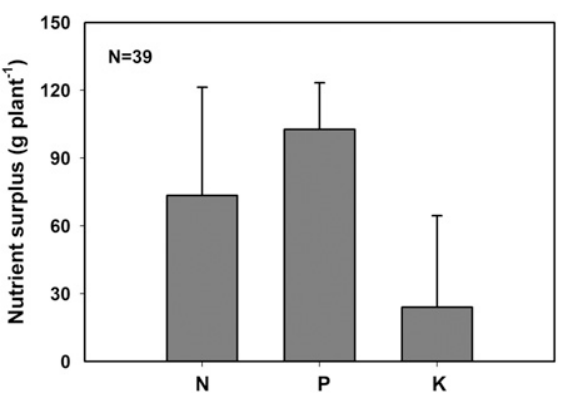

Fig. 3. The surplus of fertilizer nutrients nitrogen $(\mathrm{N})$, phosphorus $(\mathrm{P})$, and potassium $(\mathrm{K})$ in macadamia production in China. The surplus values represented the difference between the current farming practice $(n=39)$ and optimal requirements. Each value is the mean of 39 replicates $( \pm \mathrm{SE})$. Note: The data of farmers' fertilizer inputs (314 $\mathrm{g}$ of $\mathrm{N}, 127 \mathrm{~g}$ of P, $247 \mathrm{~g}$ of $\mathrm{K}$ ) in the orchards were collected from our farmer's survey across 39 farm field sites in southern China (covering about 5000 ha). We estimated the optimal nutrient requirements of macadamia (241 $\mathrm{g}$ of $\mathrm{N}, 24 \mathrm{~g}$ of $\mathrm{P}, 223 \mathrm{~g}$ of $\mathrm{K}$ ) based on the amounts of nutrients removed from soil by harvested nuts and additional growth of canopy per year for mature macadamia trees. Dry mass and concentration of nutrients in macadamia roots, stem, and leaves come from Chen et al. (2010, 2016). This paper used a target yield of macadamia nuts of $35 \mathrm{~kg}$ of fresh weight per bearing tree. Total nutrient contents in 100 $\mathrm{kg}$ of fresh nuts were based on the previous report by Nagao et al. (1992). The surplus of fertilizer nutrients $\mathrm{N}, \mathrm{P}$, and $\mathrm{K}$ (farmers' input macadamia requirement) in macadamia production is $73 \mathrm{~g}$ of $\mathrm{N}, 103 \mathrm{~g}$ of $\mathrm{P}$, and $24 \mathrm{~g}$ of $\mathrm{K}$.
With increasing planting area and expanding nut production for macadamia, it is critical to develop applicable nutrient-management strategies and technical approaches in macadamia orchards toward sustainable production. The main problems that China's macadamia industry faces are as follows:

1. Optimizing nutrient management to increase nutrient-use efficiency and macadamia nut yield through maximizing root/rhizosphere biological efficiency.

2. Developing sustainable macadamia orchards under the context of the national strategic policy of "green development."

\section{Root Growth and Rhizosphere Processes for Increasing Nutrient-use Efficiency}

Macadamia can develop cluster roots (Bright et al., 2016; Hue, 2009), portions of lateral roots bearing bottle-brush-like clusters with a high density of rootlets (Fig. 4A), under low-P environments (Dinkelaker et al., 1995). These cluster roots are efficient in $P$ mobilization and acquisition in low-P soils (Hue, 2009). At adequate $P$ supply, the formation of cluster roots can be suppressed (Fig. 4B), leading to relatively weak rhizosphere effects (Lambers et al., 2015; Lamont, 1972), for example, the reduction of carboxylate exudation (Fig. 4C). Furthermore, most Proteaceae species have a low ability to down-regulate P uptake (de Campos et al.,
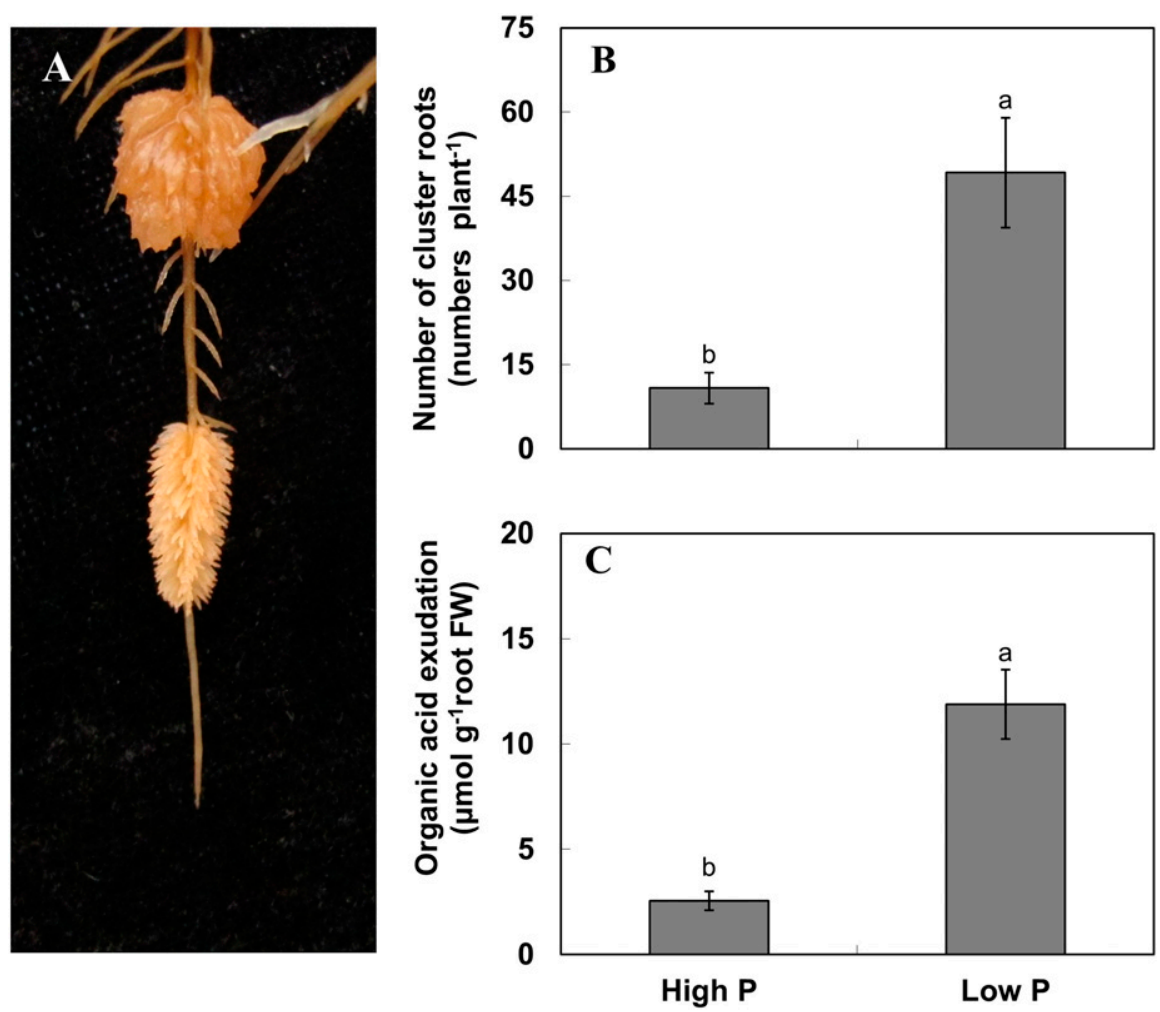

Fig. 4. Effects of $P$ supply on root growth and root exudation of macadamia. Cluster roots of macadamia grown at $10 \mu \mathrm{M}$ P supply (A), the number of cluster roots $(\mathbf{B})$, and organic acid exudation of macadamia roots (C) at $100 \mu \mathrm{M} \mathrm{P}$ (high P) and $10 \mu \mathrm{M} \mathrm{P}$ (low P) supplies, respectively. Each value is the mean of four replicates $( \pm \mathrm{SE})$, and different letters denote significant differences among treatments $(P \leq 0.05) . \mathrm{FW}=$ fresh weight; $\mathrm{P}=$ phosphorus.
2013), thus causing $P$ toxicity easily when $P$ supply is high in soil. Because of its specific biological characteristics, macadamia can mine $\mathrm{P}$ from the soil by the cluster root formation and carboxylates exuded from the roots. Thus, high $\mathrm{P}$ application rates in the macadamia orchard could cause a great waste of $\mathrm{P}$ resources. Integrating the biological characteristics of macadamia with effective nutrient management is important to achieve high yield and high nutrient-use efficiency for sustainable macadamia production.

It is still unclear whether macadamia, which can develop cluster roots, is a mycorrhizal plant. Mycorrhizal research in fruit trees commenced in 1885 (Frank, 2005). Mycorrhizas help trees to absorb nutrients through enlarging the root-absorption area, especially for $\mathrm{P}$, which has a low mobility in the soil (Marschner, 1995). Casuarinaceae, Betulaceae, Fabaceae, Myricaceae, and Cyperaceae, which develop cluster roots (Shane and Lambers, 2005; Skene, 1998; Vance, 2008), also can be infected by mycorrhizal fungi (Lambers et al., 2006; Vance, 2008). Proteaceae has been regarded as nonmycorrhizal plants in the past years (Lambers et al., 2006; Neumann and Martinoia, 2002; Skene, 1998; Vance, 2008). Lambers et al. (2006) speculated that the distribution of these species could be related to soil $\mathrm{P}$ availability. Proteaceae usually grows in the soil where the soil $\mathrm{P}$ concentration is very low. Mycorrhizal plants such as Myrtaceae appear where the soil $\mathrm{P}$ availability is suboptimal but not extremely limited. Where the soil $\mathrm{P}$ concentration is in between, Casuarinaceae dominates, which has mycorrhizas as well as cluster roots (Lambers et al., 2006). In Hakea verrucosa $\mathrm{F}$. Muel, a plant species belonging to Proteaceae that lives in the ultramafic soils having high nickel (Ni) and low $\mathrm{P}$ contents, mycorrhizal structures have been observed. In this situation, the most important function of mycorrhizas is to reduce the uptake of $\mathrm{Ni}$ to avoid Ni toxicity, because cluster roots have a strong ability to acidify the rhizosphere, increasing the availability of not only $\mathrm{P}$ but also Ni to plants (Boulet and Lambers, 2005). Some other Proteaceae plants, e.g., Banksia ericifolia (Pattinson and McGee, 2004) and Placospermum coriaceum (Shane and Lambers, 2005), can form weak symbioses with mycorrhizas.

Further confirmation is still needed about when mycorrhizal fungi start to develop an association with macadamia roots. It is worth exploring how the mycorrhizas coordinate with the cluster roots of macadamia in coping with low-P stress.

\section{Current Fertilizer Regimes in China and Opportunities for Improving Nutrient- management Approaches}

Strategies for nutrient acquisition can be efficiently used to optimize root-zone nutrient management in macadamia orchards to achieve sustainable production with the concept of "producing more with less" (Jiao et al., 2016; Shen et al., 2011, 2013). The key 


\section{(3oot/rhizosphere biological interactions}

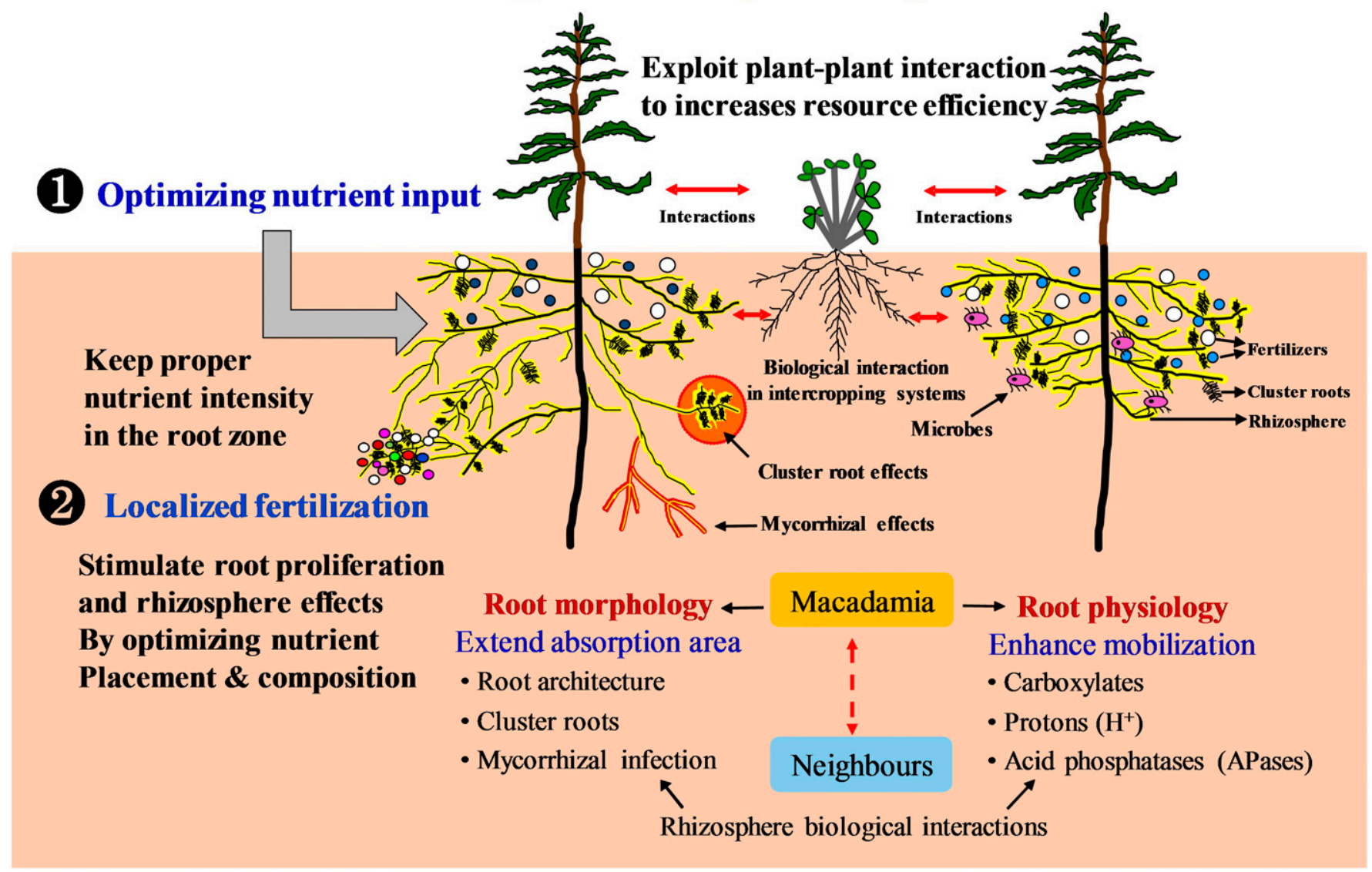

Fig. 5. Strategies of rhizosphere management for macadamia. The key components include 1) optimizing nutrient input to keep a proper nutrient supply intensity in the root zone, 2) using localized nutrient supply by band fertilization to stimulate root proliferation and rhizosphere effects through optimizing nutrient placement and compositions, and 3) exploring root/rhizosphere biological interactions to maximize nutrient-use efficiency.
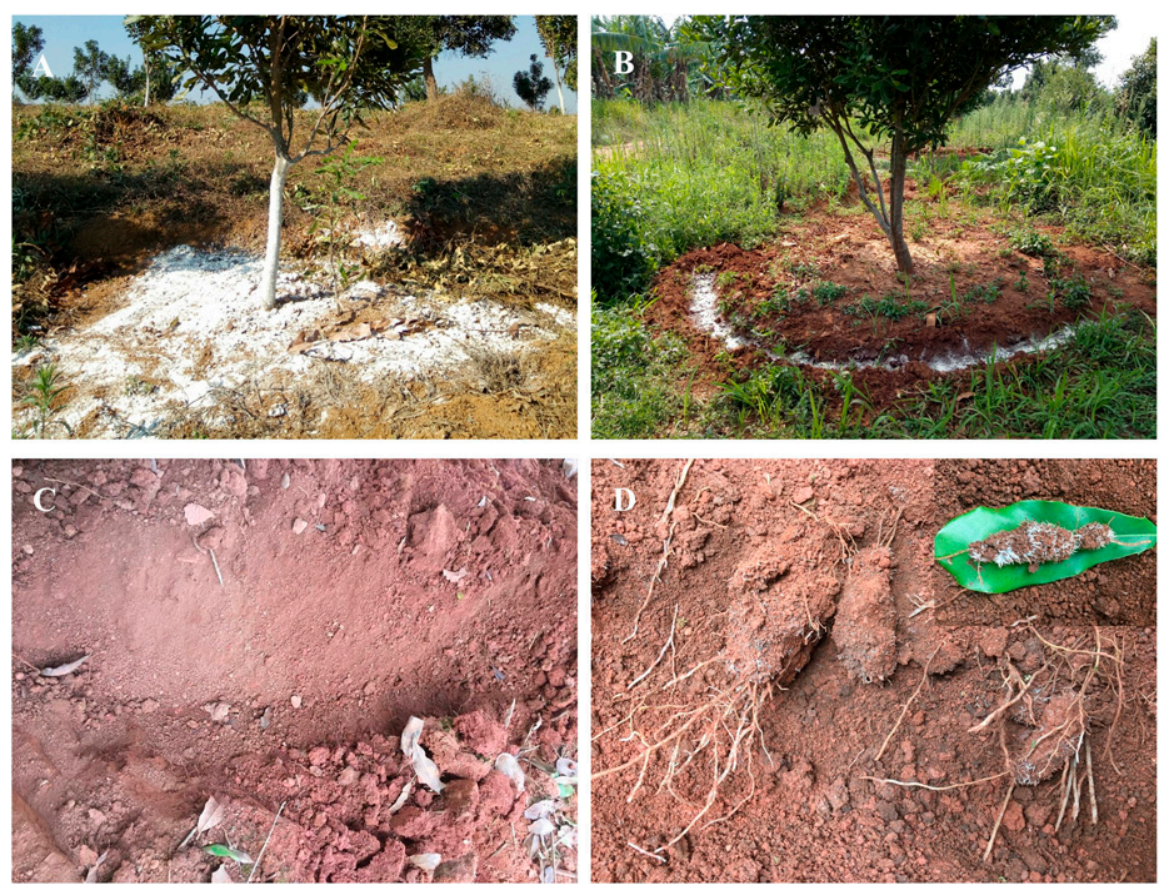

Fig. 6. Effects of $\mathrm{P}$ fertilization on root growth of macadamia. The farmers' practice fertilizer input $(\mathbf{A}, \mathbf{C})$ and optimized fertilization treatment (localized supply of lower P) (B, D), and the treatment effects on root growth $(\mathbf{C}, \mathbf{D})$ of macadamia in Yunnan, South China (lat. $21^{\circ} 58^{\prime} 44^{\prime \prime} \mathrm{N}$, long. 100 $\left.37^{\prime} 23^{\prime \prime} \mathrm{E}\right) . \mathrm{P}=$ phosphorus. components for root/rhizosphere-based nutrient management include 1) optimizing total nutrient input to a critical level to maximize root/rhizosphere efficiency, 2) improving localized nutrient supply to induce root proliferation and strengthen rhizosphere effects through changing nutrient composition and supply intensity, and 3) exploring biological interactions to enhance nutrientuse efficiency (Fig. 5).

First, controlling total nutrient application rates is critical to keep an appropriate nutrient supply level in the root zone for optimal root and shoot growth through maximizing root/ rhizosphere efficiency so that nutrient supply from soil and fertilizers and plant demand are balanced (Fig. 5). One of the more important approaches for nutrient management in China is to decrease the input of $\mathrm{P}$ fertilizers due to low-P demand by macadamia (Fig. 5). The use efficiency of $\mathrm{P}$ will be improved by increasing $\mathrm{P}$ bioavailability of macadamia with low-P input. According to our calculations, bearing macadamia tree need about 56 $\mathrm{g}$ of $\mathrm{P}$ per plant annually in the southern China. The application of chemical fertilizers in macadamia orchards is recommended in combination with organic fertilizers such as manure, compost, and decomposed straw or husk (Quinlan, 2007), especially after nut 
harvest. The application of organic fertilizers favors soil aggregate stability that can improve soil fertility (Bronick and Lal, 2005) and has been shown to increase total sugar content in plants in the pear orchard (Song et al., 2012).

Second, localized fertilization is one of the most important rhizosphere-management strategies (Fig. 5). Localized supply of nutrients in the root zone of plants can significantly stimulate root proliferation due to root sensing and foraging strategies to local nutrients, such as $\mathrm{P}$, ammonium, and nitrate (Jing et al., 2010, 2012; Shen et al., 2011, 2013). Drew (1975) found that localized supply of the nutrients in the patch significantly stimulated lateral root growth. Localized application of $\mathrm{P}$ and ammonium improves the growth of maize seedlings by stimulating root proliferation and rhizosphere acidification because ammonium uptake can induce proton release and lower the rhizosphere $\mathrm{pH}$ to further enhance $\mathrm{P}$ mobilization and use efficiency in the localized patches (Jing et al., 2010, 2012). However, in the macadamia farming practice in China, growers mostly broadcast fertilizers on the soil surface, resulting in low fertilizer-use efficiencies. We recommend that furrowband application of fertilizers (fertilizers are applied into a 10 - to $15-\mathrm{cm}$ deep furrow as a localized supply of nutrients) could be more suitable for these mountainous situations. Our experimental data also showed that fertilization in furrow-band with lower nutrient input compared with farmers can greatly stimulate active root proliferation in the localized fertilizer zone based on the rootforaging strategy for heterogeneous nutrient environment (Fig. 6). The preliminary results showed that optimal fertilization increased nut production by $5 \mathrm{~kg}$ per tree compared with farmer practice (Fig. 7). In north China, localized application of nutrients in the root zone of fruit trees is practiced through burying a few rows of porous bricks or other media (to adsorb nutrients) with a large gap in a 0.6-m depth soil profile (Yan et al., 2015) and then applying manure, straw, and even microelement fertilizers in the local site to promote root growth or overcome iron and zinc deficiency (Jing et al., 2012). Another way is to bury porous ceramic pots and fill with nutrient solution so that nutrients can release gradually from the pots to the root zone. All these approaches of localized nutrient supply for the orchard have exhibited an efficient effect of rhizosphere management on improving root development and tree growth.

Third, the selection of appropriate plant species intercropped with macadamia by maximizing root-root biological interactions plays an important role in the rhizosphere management for sustainable production (Fig. 5). Intercropping generally appears in cereal crops; when maize is intercropped with faba bean, the yields and P-use efficiency for both crops can be increased due to root-rhizosphere interactions (Zhang et al., 2016). Faba bean has strong rhizosphere effects by exuding citrate and acid phosphatase to the rhizosphere, and it can mobilize $\mathrm{P}$ from calcareous soils by root physiological strategies, causing the increased $\mathrm{P}$ uptake by neighboring maize plants (Zhang et al., 2016). Rubber trees intercropped with banana in a young rubber orchard can greatly increase farm income through taking full advantage of land resources and also promoting the growth of rubber trees (Wu et al., 2009). In southern China, diverse intercropping systems of macadamia have been built at the early establishment stages of the orchard. Farmers try to intercrop macadamia with coffee, tea, peanuts, maize, and even banana. It has been proven that greater yield and economic benefits are achieved in the macadamia intercropping with coffee (Perdoná and Soratto, 2015), which even helps to improve biodiversification (Perdoná and Soratto, 2016).

We also used the forward-looking infrared camera to take the images of maize intercropped with macadamia. The digital image analysis showed that the intercropping of maize and macadamia plants significantly reduced the land surface temperature of orchards and improved the ecological environmental conditions of orchards (Fig. 8A-C). The temperature of the bare land could reach around $28.7^{\circ} \mathrm{C}$, but if planted with maize, the temperature decreased to $24.7^{\circ} \mathrm{C}$. This is critical for improving fertilizer-use efficiency and fruit setting by influencing pollen germination and fertilization in southwest China during hot summer periods. Previous studies showed that total dry weight of macadamia responded to temperature. Optimum temperature is between 20 and $25^{\circ} \mathrm{C}$ for the tree growth and dry matter accumulation (Nagao et al., 1992; Trochoulias and Lahav, 1983). The developing leaves become chlorotic and later die at $30{ }^{\circ} \mathrm{C}$, and macadamia tree growth ceases at 10 or $35{ }^{\circ} \mathrm{C}$ (Nagao et al., 1992; Trochoulias and Lahav, 1983). Further benefits, including increasing $\mathrm{N}_{2}$ fixation, $\mathrm{P}$ mobilization, soil organic matter and soil biodiversity, and retaining soil moisture, need to be proven in future work.

\section{Conclusions}

Macadamia production is increasing rapidly in the world. China has the largest planting area now. Agronomic management and sustainable development of macadamia orchards are urgently needed. It is critical for achieving the target "high production and high efficiency" to develop root/rhizosphere nutrient management strategies, including root-zone system management to keep a proper nutrient supply intensity, local nutrient management, and maximizing biological interactions of the rhizosphere. This paper introduces the current problems of macadamia production in China from the point of view of plant nutrition. We put forward rhizosphere-management strategies and the direction of sustainable development of macadamia orchards, which provides an important basis for the development of macadamia industry.

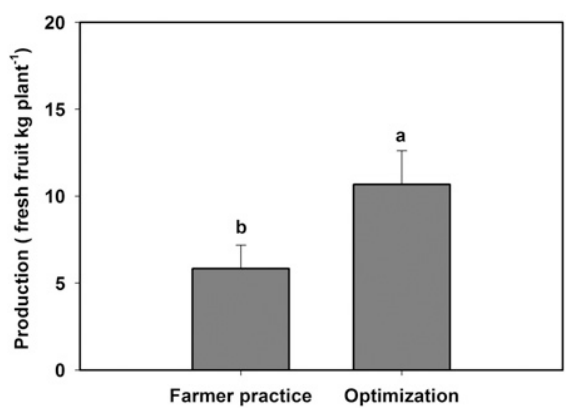

Fig. 7. Macadamia production of farmer practice and optimal fertilization. Different letters denote a significant difference between them $(P \leq 0.05)$. Note: The production data were based on a field comparative experiment between farmers' practices and the recommended optimal fertilization. The optimal fertilization was set according to the nutrient requirements (241 g of nitrogen, $24 \mathrm{~g}$ of phosphorus, $223 \mathrm{~g}$ of potassium per tree annually) and localized supply recommended. The experiment was conducted in Yunnan, South China (lat. $21^{\circ} 58^{\prime} 44^{\prime \prime} \mathrm{N}$, long. $100^{\circ} 37^{\prime} 23^{\prime \prime} \mathrm{E}$ ). The experimental plot was $1334 \mathrm{~m}^{2}$ and covered 40 bearing trees. The fresh nuts were harvested and yields were recorded for optimal treatments and farmers' fertilization, respectively.
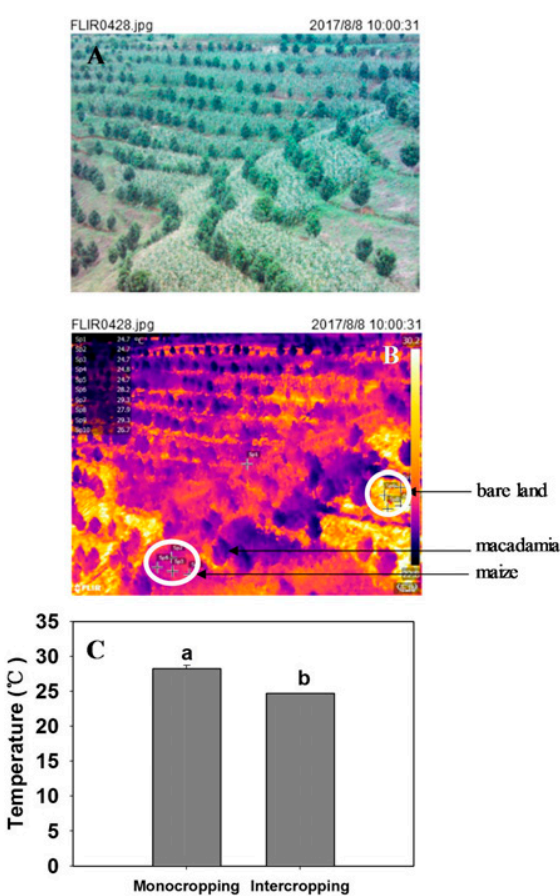

Fig. 8. Macadamia intercropping with maize (A), associated infrared temperature map (B), and the temperature of monocrop and intercropping (C). Different letters in (C) denote significant differences between monocrop and intercropping or with and without cover crops $(P \leq 0.05)$ Note: a forward-looking infrared camera was used to record the images of maize/macadamia intercropping. The "FLIR Tools" was used to analyze the images. We chose five spots of maize and bare land, respectively, to calculate the average temperature values. The $t$ test was performed using SAS statistical software (8.1; SAS Institute, Inc., Cary, NC). Significant differences among means were separated by least significant difference $(P \leq 0.05)$. 


\section{Literature Cited}

Bittenbender, H.C. and H.H. Hirae. 1990. Common problems of macadamia nut in Hawaii. University of Hawaii, Honolulu.

Boulet, F.M. and H. Lambers. 2005. Characterisation of arbuscular mycorrhizal fungi colonisation in cluster roots of shape Hakea verrucosa F. Muell (Proteaceae), and its effect on growth and nutrient acquisition in ultramafic soil. Plant Soil 269:357-367.

Bright, J., S. Alt, and R. Commens. 2016. Macadamia integrated orchard management practice guide 2016. New South Wales Department of Primary Industries, New South Wales.

Bronick, C.J. and R. Lal. 2005. Soil structure and management: A review. Geoderma 124:3-22.

de Campos, M.C.R., S.J. Pearse, R.S. Oliveira, and H. Lambers. 2013. Downregulation of net phosphorus-uptake capacity is inversely related to leaf phosphorus-resorption proficiency in four species from a phosphorus-impoverished environment. Ann. Bot. 111:445-454.

Chen, G.Y., C. Zhou, W.H. Li, G.H. Kong, X.M. Xiao, and H. Yue. 2010. Primary study on mineral element distribution in macadamia trees. Guangdong Agricultural Sci. 37:75-76.

Chen, J., C.Z. Lu, L.Q. Du, W.Q. Shi, D.X. Zhao, A.M. Xian, and W.L. Wang. 2016. Biomass composition features in different-year-old macadamia tree. Guizhou Agricultural Sci. 44:106-109.

Dinkelaker, B., C. Hengeler, and H. Marschner. 1995. Distribution and function of proteoid roots and other root clusters. Bot. Acta 108:183-200.

Drew, M.C. 1975. Comparison of the effects of a localized supply of phosphate, nitrate, ammonium and potassium on the growth of the seminal root system, and the shoot, in barley. New Phytol. 75:479-490.

Duke, J.A. 2001. Macadamia Spp. handbook of nuts. CRC Press, Boca Raton, FL.

Frank, B. 2005. On the nutritional dependence of certain trees on root symbiosis with belowground fungi (an English translation of A.B. Frank's classic paper of 1885). Mycorrhiza $15: 267-275$

He, X.Y., L. Tao, J. Liu, and S.B. Ni. 2017. General situation and trend of macadamia industry at home and abroad. Ind. Dev. 74:4-11.

Hue, N.V. 2009. Iron and phosphorus fertilizations and the development of proteoid roots in macadamia (Macadamia integrifolia). Plant Soil 318:93-100.

International Nut and Dried Fruit Council. 2016/ 2017. Macadamia. 11 July 2017. <https://www. nutfruit.org/>.

Jiao, X.Q., Y. Lyu, X.B. Wu, H.G. Li, L.Y. Cheng, C.C. Zhang, L.X. Yuan, B.X. Jiang, R.F. Jiang, B.W. Jiang, Z. Rengel, F.S. Zhang, W.J. Davies, and J.B. Shen. 2016. Grain production versus resource and environmental costs: Towards increasing sustainability of nutrient use in China. J. Expt. Bot. 67:4935-4949.

Jing, J.Y., Y. Rui, F.S. Zhang, Z. Rengel, and J.B. Shen. 2010. Localized application of phosphorus and ammonium improves growth of maize seedlings by stimulating root proliferation and rhizosphere acidification. Field Crops Res. 119:355-364.

Jing, J.Y., F.S. Zhang, Z. Rengel, and J.B. Shen. 2012. Localized fertilization with $\mathrm{P}$ plus $\mathrm{N}$ elicits an ammonium-dependent enhancement of maize root growth and nutrient uptake. Field Crops Res. 133:176-185.

Ko, W.H. 2009. Nature of slow and quick decline of macadamia trees. Bot. Stud. 50:1-10.

Lambers, H., M.W. Shane, M.D. Cramer, S.J. Pearse, and E.J. Veneklaas. 2006. Root structure and functioning for efficient acquisition of phosphorus: Matching morphological and physiological traits. Ann. Bot. 98:693-713.

Lambers, H., P.L. Clode, H. Hawkins, E. Laliberté, R.S. Oliveira, P. Reddell, M.W. Shane, M. Stitt, and P. Weston. 2015. Metabolic adaptations of the non-mycotrophic Proteaceae to soils with low phosphorus availability. Annu. Plant Rev. 48:289-336.

Lamont, B.B. 1972. The effect of soil nutrients on the production of proteoid roots by Hakea species. Austral. J. Bot. 20:27-40.

Marschner, H. 1995. Mineral nutrition of higher plants. 2nd ed. Academic Press, London.

Nagao, M.A., H.H. Hirae, and R.A. Stephenson. 1992. Macadamia: Cultivation and physiology. Crit. Rev. Plant Sci. 10:441-470.

Neumann, G. and E. Martinoia. 2002. Cluster roots - an underground adaptation for survival in extreme environments. Trends Plant Sci. $7: 162-167$.

O'Hare, P., K. Quinlan, R. Stephenson, and N. Vock. 2004. Growing guide: Macadamia grower's handbook. Queensland Department of Primary Industries. Brisbane.

Pattinson, G.S. and P.A. McGee. 2004. Influence of colonisation by an arbuscular mycorrhizal fungus on the growth of seedlings of Banksia ericifolia (Proteaceae). Mycorrhiza 14:119125

Peace, C.P., V. Vithanage, C.G.N. Turnbull, and B.J. Carroll. 2003. A genetic map of macadamia based on randomly amplified DNA fingerprinting (RAF) markers. Euphytica 134:17-26.

Perdoná, M.J. and R.P. Soratto. 2015. Soratto higher yield and economic benefits are achieved in the macadamia crop by irrigation and intercropping with coffee. Scientia Hort. 185:59-67.

Perdoná, M.J. and R.P. Soratto. 2016. Arabica coffee-macadamia intercropping: A suitable macadamia cultivar to allow mechanization practices and maximize profitability. Agron. J. 108:2301-2312.
Quinlan, K. 2007. Organic macadamia growing. Primefact 685. New South Wales Department of Primary Industries, New South Wales.

Quinlan, K. and P. Wilk. 2005. Macadamia culture in NSW. Primefact 5. New South Wales Department of Primary Industries, New South Wales.

Shane, M.W. and H. Lambers. 2005. Cluster roots: A curiosity in context. Plant Soil 274:101-125.

Shen, J.B., L.X. Yuan, J.L. Zhang, H.G. Li, Z.H. Bai, X.P. Chen, W.F. Zhang, and F. Zhang. 2011. Phosphorus dynamics: From soil to plant. Plant Physiol. 156:997-1005.

Shen, J.B., C. Li, G.H. Mi, L. Li, L.X. Yuan, R.F. Jiang, and F.S. Zhang. 2013. Maximizing root/ rhizosphere efficiency to improve crop productivity and nutrient use efficiency in intensive agriculture of China. J. Expt. Bot. 64:1181-1192.

Skene, K.R. 1998. Cluster roots: Some ecological considerations. J. Ecol. 86:1060-1064.

Song, X.H., K. Xie, H.B. Zhao, Y.L. Li, C.X. Dong, Y.C. Xu, and Q.R. Shen. 2012. Effects of different organic fertilizers on tree growth, yield, fruit quality, and soil microorganisms in a pear orchard. Eur. J. Hort. Sci. 77:204-210.

Stephenson, R. 2005. Macadamia: Domestication and commercialisation. Chronica Hort. 45:11-15.

Storey, W.B. and R.A. Hamilton. 1953. Macadamia nut industry in Hawaii. California Avocado Soc. Yrbk. 38:63-67.

Trochoulias, T. and E. Lahav. 1983. The effect of temperature on growth and dry-matter production of macadamia. Scientia Hort. 19:167176.

Trueman, S.J. 2013. The reproductive biology of macadamia. Scientia Hort. 150:354-359.

Vance, C.P. 2008. Plants without arbuscular mycorrhizae, p. 117-142. In: P.J. White and J.P. Hammond (eds.). The ecophysiology of plantphosphorus interactions. Springer Netherlands, Dordrecht.

Wu, Z.X., G.S. Xie, Z.L. Tao, Z.D. Zhou, and J.H. Cao. 2009. Characteristics of photosynthesis and water physio-ecology of rubber trees and intercrop banana in young rubber plantations. Trop. Agricultural Eng. 33:54-58.

Yan, Y.J., J. Bai, C.X. Fu, X.D. Fan, Y.A. Wang, X.D. Chen, and H.R. Shu. 2015. Effects of water-storage regulation around root on photosynthetic characteristics and antioxidant enzyme activities of apple leaves. Acta Horticulturae Sinica. 42:817-825.

Zhang, D., C. Zhang, X. Tang, H. Li, F. Zhang, Z. Rengel, W.R. Whalley, W.J. Davies, and J.B. Shen. 2016. Increased soil phosphorus availability induced by faba bean root exudation stimulates root growth and phosphorus uptake in neighbouring maize. New Phytol. 209:823831. 